\title{
Disintegration per Minute per 100 milligrams
}

National Cancer Institute

\section{Source}

National Cancer Institute. Disintegration per Minute per 100 milligrams. NCI Thesaurus. Code C117968.

A unit of radioactive decay expressed in atoms of radioactive material that decay over a period of time equal to sixty seconds in a mass unit equal to one centigram. 